\title{
Profiling of D-alanine production by the microbial isolates of rat gut microbiota
}

Cindy J. Lee ${ }^{1, \#, ~ T i a n ~ A . ~ Q i u ~}{ }^{1, \#}$, Zhilai Hong ${ }^{2, \#}$, Zhenkun Zhang ${ }^{2}$, Yuhao Min ${ }^{1}$, Linzixuan Zhang ${ }^{1}$, Lei Dai ${ }^{2}$, Huimin $\mathrm{Zhao}^{1}$, Tong $\mathrm{Si}^{2}{ }^{2}$, Jonathan V. Sweedler, ${ }^{1, *}$

${ }^{1}$ Department of Chemistry, Carl R. Woese Institute for Genomic Biology, and the Beckman Institute, University of Illinois Urbana-Champaign, Urbana, IL 61801, United States

${ }^{2}$ CAS Key Laboratory of Quantitative Engineering Biology, Shenzhen Institute of Synthetic Biology, Shenzhen Institute of Advanced Technology, Chinese Academy of Sciences, Shenzhen 518055, China

*Corresponding authors.

jsweedler@illinois.edu (Jonathan V. Sweedler)

tong.si@siat.ac.cn (Tong Si)

\#C.J.L., T.A.Q, and Z.L.H. are co-first authors with equal contribution to the work.

Running title

- D-Alanine production from rat gut microbial strains 


\begin{abstract}
D-alanine (D-Ala) and several other D-amino acids (D-AAs), unusual amino acids present in mammals, act as hormones and neuromodulators in nervous and endocrine systems. Unlike the endogenously synthesized Dserine in animals, D-Ala may be from exogenous sources, e.g., diet and intestinal microorganisms. However, it is unclear if the capability to produce D-Ala and other D-AAs varies among different microbial strains in the gut. We isolated individual microorganisms of rat gut microbiota and profiled their D-AA secretion in vitro, focusing on D-Ala. Serial dilutions of intestinal content from adult male rats were plated on agar to obtain clonal cultures. Using MALDI-TOF MS for rapid strain typing, we identified 38 unique isolates, grouped into 11 species based on 16S rRNA gene sequences. We then used two-tier screening to profile bacterial D-AA secretion, combining a D-amino acid oxidase-based enzymatic assay for rapid assessment of overall D-AA amount, followed by chiral LC-MS/MS to quantify individual D-AAs, revealing 19 out of the 38 isolated strains as D-AA producers. LCMS/MS analysis of the eight top D-AA producers showed high levels of D-Ala in all strains tested, with substantial inter- and intra-species variations. Though results from enzymatic assay and LC-MS/MS analysis aligned well, LC-MS/MS further revealed the existence of D-glutamate and D-aspartate, which are poor substrates for enzymatic assay. We observed large inter- and intra-species variation of D-AA secretion profiles from rat gut microbiome species, demonstrating the importance of chemical profiling of gut microbiota in addition to sequencing, furthering the idea that microbial metabolites modulate host physiology.
\end{abstract}

Keywords: D-alanine, amino acid, rat, microbiome, Bacillus, host-microbe, chiral analyses, mass spectrometry 


\section{Introduction}

Microbial metabolites from gut microbiota have been reported to modulate the host's immune, endocrine, and nervous systems as well as metabolic homeostasis (1-3). For example, gut microbiota-derived short-chain fatty acids can regulate gut immunity, host metabolism, and enteric nervous systems (2). Other examples include aromatic amino acids (AAs) (1) and neurotransmitters such as gamma-aminobutyric acid (4). The study of hostassociated microbial metabolites is therefore key to understanding host-microbe interactions and opens new avenues for future biomedicines and therapeutics.

One enigmatic set of molecules from both host and microbial metabolism is the D-amino acids (D-AAs). Unlike the prevalence of L-amino acids (L-AAs), which are the building blocks of proteins, D-AAs exist in trace amounts in the biofluids, tissues, and organs of mammals (5). The biological roles and biosynthetic pathways of D-AAs are less understood than many other metabolites. The most studied D-AA in mammals, D-serine (D-Ser), is a neurotransmitter and a potential endocrine modulator produced by serine (Ser) racemases in the brain and pancreas $(6,7)$. D-Ser is a potent co-agonist of the N-methyl-D-aspartate receptor (NMDAR), which is an ionotropic glutamate receptor important for the long-term potentiation of synaptic transmissions (8). Besides DSer, D-aspartate (D-Asp) can also activate NMDAR as an agonist and has been found in nervous and endocrine tissues. Some evidence shows D-Asp is also related to testosterone synthesis (9-11). D-alanine (D-Ala), another potent NMDAR co-agonist, has been found in many parts of the animal body, including the insulin-secreting beta-cells and adrenocorticotropic hormone-secreting cells in the pituitary $(12,13)$. In addition, D-Ala release from rat islets of Langerhans upon glucose stimulation has been demonstrated (14).

With the physiological relevance of many D-AAs being revealed, it is important to understand their source. Endogenous enzymes, such as Ser and aspartate (Asp) racemases, have been found in animals; these enzymes convert L-serine and L-aspartate to their corresponding D-forms $(6,15,16)$. Microbiota have been recognized as another important source of D-AAs in animals. Microorganisms encode a large variety of AA racemases, such as those for alanine (Ala), Ser, glutamate (Glu), Asp, and proline (Pro). These racemases are responsible for producing D-AAs that regulate microbial processes such as cell wall synthesis and spore germination (17). By comparing germ-free (GF) and normal mice, D-Ala is believed to be mainly obtained from intestinal microorganisms (18). A metagenome-wide association study on the gut microbiota in type 2 diabetes (T2D) patients showed that several enzymes related to D-AA biosynthesis and metabolism were associated with T2D (19), indicating a potential role for microbiota-derived D-AAs in regulating glucose homeostasis. Microbiota-originated D-AAs are also shown to modify murine mucosal defense by inducing D-amino acid oxidase (DAAO) expression in the gut tissue (20), as well as to suppress sinonasal innate immune responses through sweet taste receptors (21).

The composition of gut microbiota changes in response to environmental factors, such as diet, leads to changes in microbial metabolite profiles (22). It is critical to identify major microbial producers of specific metabolites that mediate host-microbiota interaction, information that supports mechanistic studies and the 
development of microbial engineering strategies for microbiome-targeting therapeutics. Here, we developed a high-throughput analytical method to isolate microbial strains from the animal gut for profiling D-AA production. Species-level variations in the amount and composition of microbial D-AA production have been noted (23). As strain-specific diversity in the gut microbiota is revealed using high-throughput approaches in microbial cultivation and functional characterization $(24,25)$, it is interesting to examine whether different strains within the same species may exhibit distinct D-AA profiles. Identification of the major D-AA producers in animal gut microbiota will help to elucidate the regulation and function of D-AA biosynthesis in the context of host-microbe interplay, to obtain culturable isolates to design mechanistic experiments, and to understand the genetic basis of strain diversity.

In this work, we identified and isolated individual microorganisms that secrete high levels of D-Ala, along with four other D-AAs from rat gut microbiota, D-proline (D-Pro), D-Ser, D-glutamate (D-Glu), and D-Asp. Serial dilutions of colon contents from adult male Sprague-Dawley rats were plated on agar media to obtain clonal cultures, which were subjected to rapid strain typing using MALDI-TOF MS. Followed by 16S rRNA sequencing analysis, 38 unique strain isolates belonging to 11 bacterial species were confirmed. A two-tier screening workflow was devised to profile D-AA production. First, a 96-well microtiter assay using a broadspectrum DAAO coupled with hydrogen peroxide detection was established for rapid assessment of neutral DAA production. Then, chiral LC-MS/MS was utilized to quantify the levels of D-Ala, D-Pro, DSer, D-Glu, and D-Asp. Substantial species and strain-specific production of various D-AA differences were observed among microbial isolates from the rat gut. These data suggest that different gut microbiota compositions may impact specific D-AA levels, especially for D-Ala, which cannot be synthesized by the host.

\section{Results}

\section{Bacterial isolates from the rat intestine}

We utilized $\mathrm{R}$ medium to isolate microbial strains from the rat gut. $\mathrm{R}$ medium permits cultivation of anaerobic bacteria in aerobic atmosphere (26) by supplementing the Schaedler agar with reducing agents, including ascorbic acid, glutathione, and uric acid. From the fresh intestinal digesta of the male adult rats, around 600 microbial isolates were

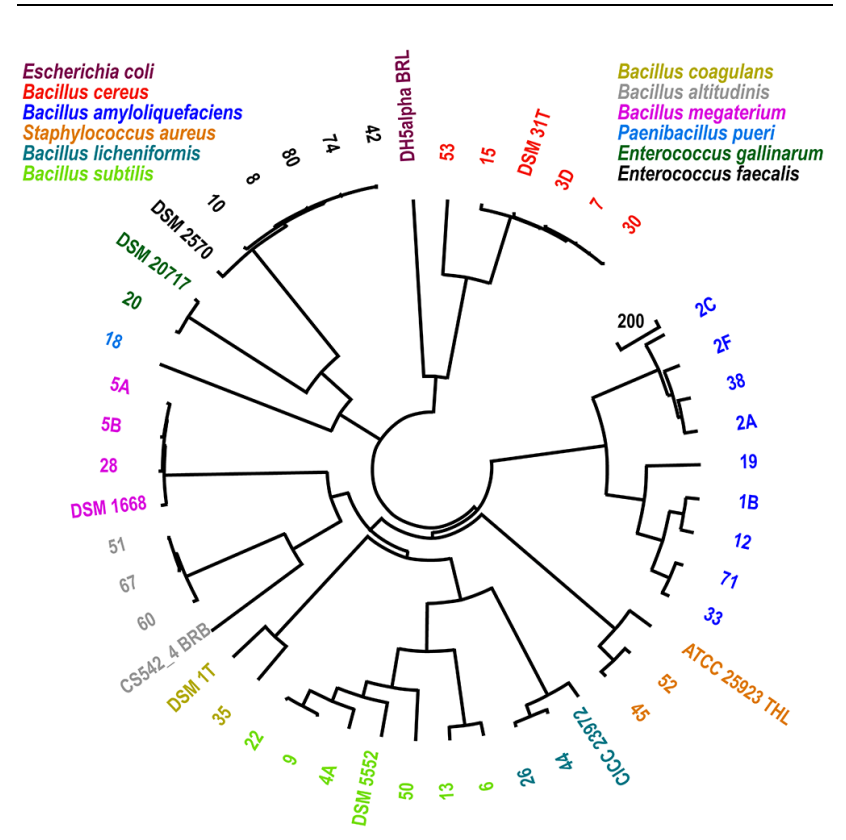

Figure 1. Class dendrogram of MALDI-TOF mass spectra of 38 microbial isolates from the rat gut. Microbial strains in the Bruker Taxonomy database were included, based on their similarities to rat isolates in spectrum pattern matching using the Bruker MALDI Biotyper 4.0 software; E. coli DH5alpha was included as an outgroup. 
obtained following serial dilutions, agar cultivation, and clone-purifying streaking. Based on MALDI-TOF MS strain typing, 38 isolates exhibiting representative, distinct spectrum patterns (Figure 1) were selected for 16S rRNA gene sequencing, which revealed 15 full-length 16S rRNA sequences grouped into 11 bacterial species, four genres (Bacillus, Staphylococcus, Enterococcus, and Paenibacillus), and one phylum (Firmicutes) (Table S1). Interestingly, the strains with different $16 \mathrm{~S}$ rRNA genes of the same species (B. amyloliquefaciens, $B$. subtilis, B. cereus) (Table S1) also tended to be grouped differently when subjected to MALDI mass spectra clustering (Figure 1). Moreover, strain typing results using MALDI-TOF MS and 16S rRNA sequencing were consistent for most rat gut isolates, except for B. amyloliquefaciens and Paenibacillus pueri, whose MALDI mass spectra did not exhibit significant similarities with those included in the Bruker Taxonomy database, version 4.0 .

\section{D-AA levels in microbial secretes by DAAO assay}

To analyze the overall production of neutral D-AAs, including D-Ala, an enzyme assay was first performed on the agar cultures of gut-sourced microbes. Because DAAO (EC 1.4.3.3) displays a wide spectrum of substrate specificity, quantification was calibrated using an external standard curve based on D-Ala and therefore reported as D-Ala equivalents (Figure 2). A 50:50 methanol: $\mathrm{ddH}_{2} \mathrm{O}$ solution was utilized as a mild extraction method for in vitro agar cultures so that extracellular metabolites were primarily analyzed. With the stated conditions and detectability, only the Bacillus and Paenibacillus strains showed observable D-AA production (Figure 2). Substantial species- and strain-level variations were also observed. For example, three of nine $B$. amyloliquefaciens, two of six B. subtilis, and two of five B. cereus strains did not show detectable D-AA secretion. No clear correlation was observed between 16S rRNA gene sequences and D-AA production (Figure 2),

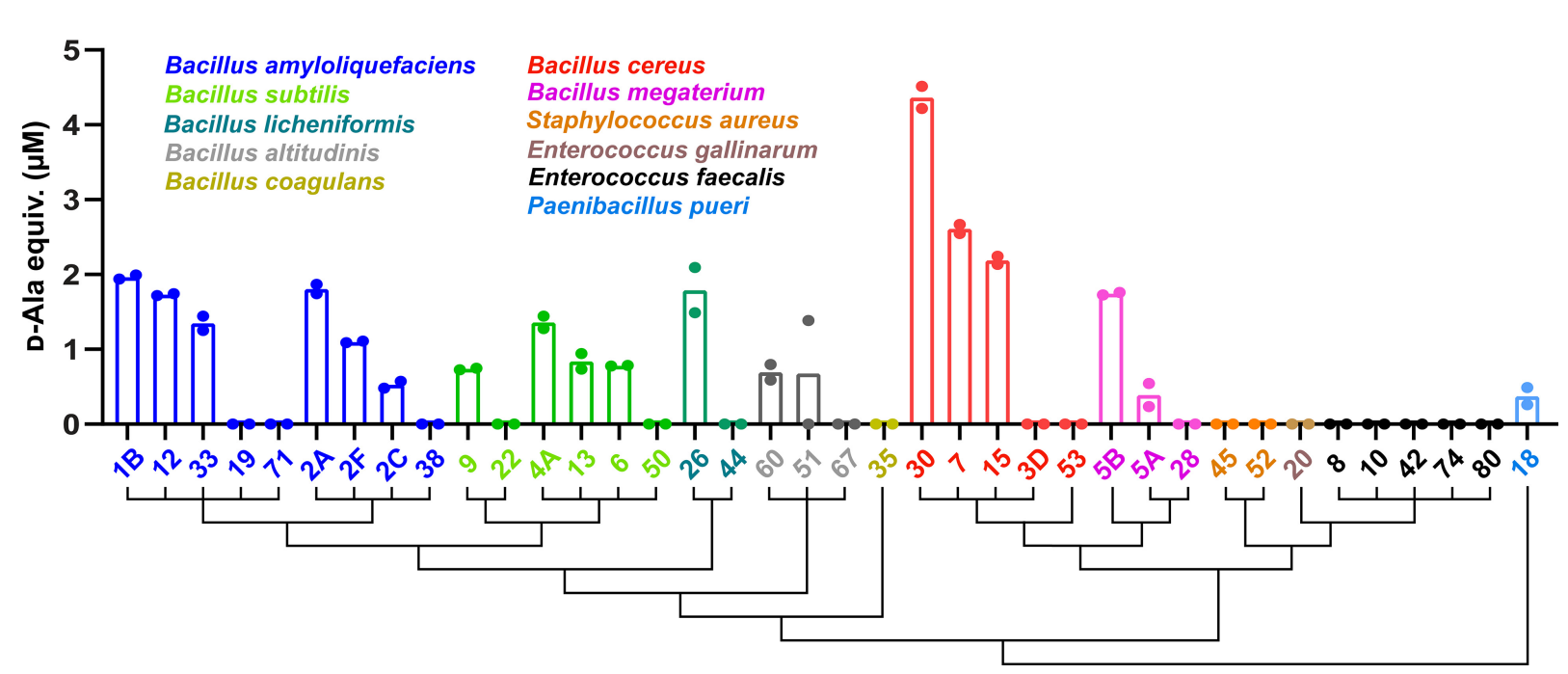

Figure 2. Secreted D-AA concentrations by rat gut isolates using the DAAO enzyme assay. Strains were grouped according to $16 \mathrm{~S}$ rRNA gene sequences (Table S1). Average and individual values of replicates are shown in bars and dots, respectively $(\mathrm{n}=2)$. 
suggesting strain-level phenotypic variations cannot be solely deduced from 16S rRNA-based microbiome sequencing analysis.

\section{LC-MS/MS analysis of Ala, Pro, Ser, Glu, and Asp in L- and D-configurations}

Because DAAO mainly catalyzes the oxidative deamination of neutral and basic D-AAs, the corresponding enzymatic assay estimated the overall sum of those D-AAs. Chiral LC-MS/MS measurements are necessary to analyze the levels of different D-AAs with improved chemical specificity. However, because of the generally low abundance of D-enantiomers of AAs, as well as the high sensitivity and limited dynamic range of the MS modality, carefully designed sample preparation steps are required to remove interfering compounds and enrich AA content before chiral LC-MS/MS analysis.

Here, we utilized strong cation exchange (SCX)-solid phase extraction (SPE) to prepare samples for LC-MS/MS. Table 1 shows the overall recovery of SCX-SPE, calculated from the average values of peak areas obtained for D-AA standards before and after SPE. The efficiency of this SPE treatment is similar for both enantiomers of a particular AA. Depending on the isoelectric point of each AA, the recovery rate varied from 30 to $100 \%$. Since this SPE treatment was performed on samples positive for the DAAO activity that focuses on DAla, D-Pro, and D-Ser, the recovery rate was acceptable.

Table 1. The overall recovery rate of selected AAs using a SCX-SPE.

\begin{tabular}{|c|c|c|c|}
\hline \multicolumn{2}{|c|}{ Amino Acids } & Isoelectric Point & \% Recovery $(\mathrm{n}=3)$ \\
\hline \multirow{2}{*}{ Asp } & $\mathrm{D}$ & \multirow{2}{*}{2.77} & $31.7 \pm 2.9$ \\
\cline { 2 - 2 } \cline { 4 - 4 } Glu & $\mathrm{L}$ & & $33.4 \pm 0.7$ \\
\hline \multirow{2}{*}{ Ser } & $\mathrm{D}$ & \multirow{2}{*}{3.22} & $55.5 \pm 2.3$ \\
\cline { 2 - 2 } & $\mathrm{L}$ & & $63.6 \pm 1.0$ \\
\hline \multirow{2}{*}{ Ala } & $\mathrm{D}$ & \multirow{2}{*}{5.68} & $53.4 \pm 1.9$ \\
\cline { 2 - 2 } \cline { 4 - 4 } & $\mathrm{L}$ & $\mathrm{D}$ & $55.7 \pm 3.3$ \\
\hline \multirow{2}{*}{ Pro } & $\mathrm{L}$ & \multirow{2}{*}{6.00} & $\approx 100 \pm 6.5$ \\
\hline & $\mathrm{D}$ & \multirow{2}{*}{6.30} & \\
\cline { 2 - 2 } & $\mathrm{L}$ & & $\approx 100 \pm 4.5 \pm 1.6$ \\
\hline
\end{tabular}

An LC-MS/MS approach was used to identify and quantitate D/L-Ala, -Pro, -Ser, -Glu, and -Asp in the gut strain samples. Each analyte peak was identified by both retention time comparison to AA standards using the multiple reaction monitoring mode and standard spiking. Representative chromatograms of D/L-AAs in a sample before and after standard spiking are shown in Figure 3. 


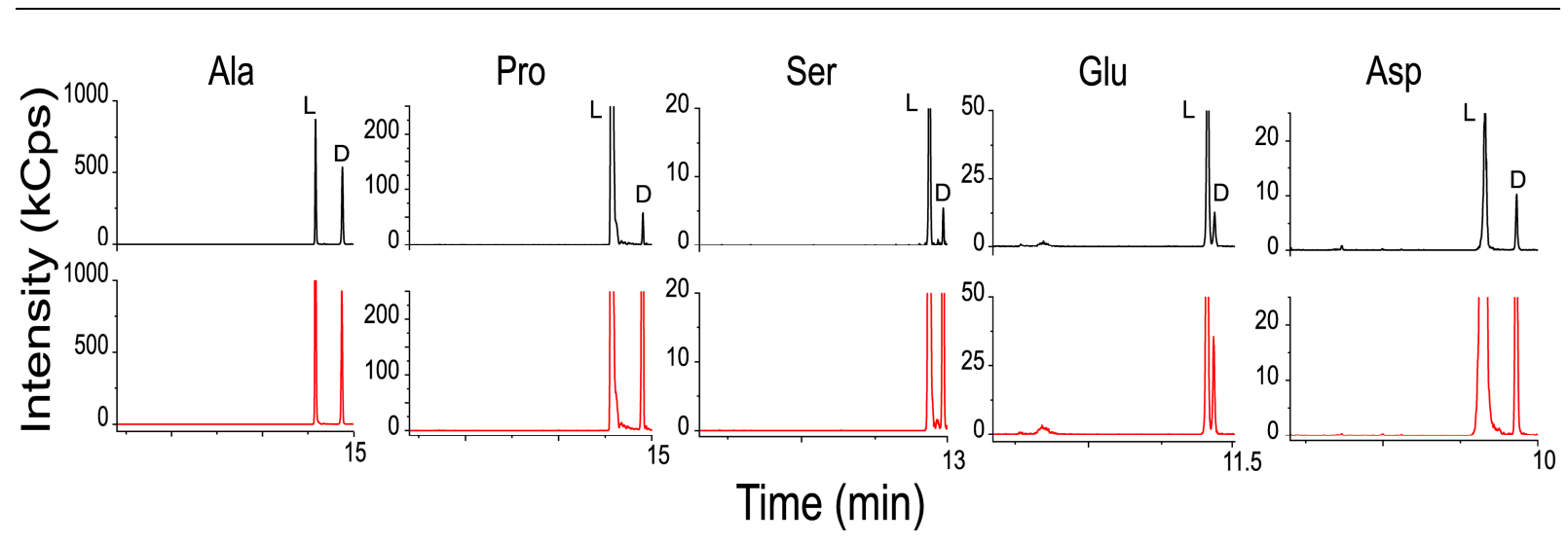

Figure 3. Representative chromatograms for D/L-Ala, Pro, Ser, Glu, and Asp. (Top) sample; (bottom) sample spiked with D/L-standards.

Using the abovementioned workflow combining SCX-SPE with LC-MS/MS, we selected eight strains exhibiting the highest DAAO assay results and analyzed their production levels of D-Ala, D-Pro, D-Ser, D-Glu, and D-Asp in the extracellular crude extracts. Figure 4 and Table 2 summarize the concentrations of D-Ala, DPro, D-Ser, D-Glu, and D-Asp, normalized by protein amount, in each sample, in addition to each D-AA by percentage, i.e., the amount of D-AA per the total corresponding AA (Table 2). The LC-MS/MS results confirmed D-Ala secretion by the select strains and revealed relatively low levels of D-Pro and D-Ser, which are also DAAO substrates. On the other hand, notable production of acidic D-Glu and D-Asp was observed for $B$. cereus (Figure 4 and Table 2). Because DAAO exhibits no or minimal activity towards acidic D-AAs, it may not be possible to find B. cereus isolates as D-Glu and D-Asp producers solely based on the DAAO assay. Whereas D-Ala and D-Glu are essential and universal components of microbial peptidoglycans, D-Asp is a less common metabolite in bacteria (27).

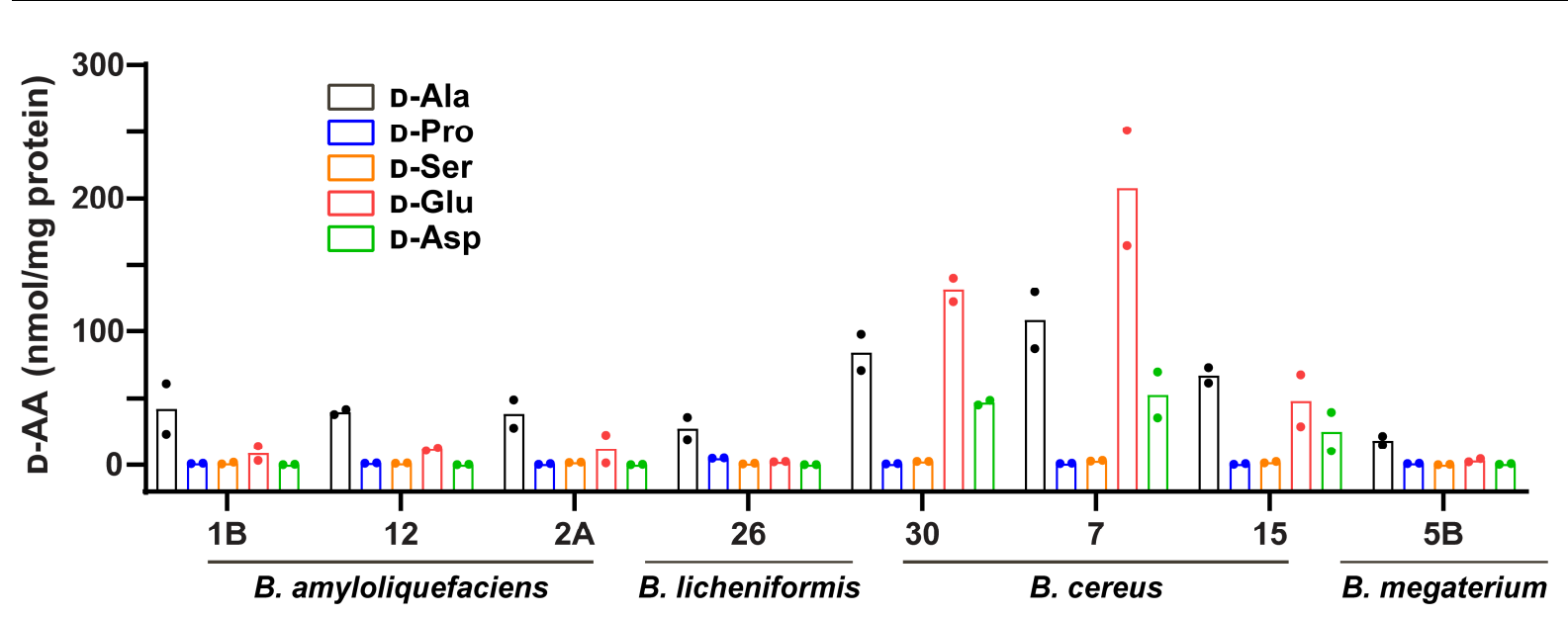

Figure 4. Free D-AAs in different gut bacterial strains (nmol/mg protein). Average and individual values of replicates are shown in bars and dots, respectively $(n=2)$. 
Table 2. Free D-AA concentrations in different gut bacterial strains (nmol/mg protein) and the D-AA ratios $(\% \mathrm{D}$ $=\mathrm{D} /(\mathrm{D}+\mathrm{L}))$.

\begin{tabular}{|c|c|c|c|c|c|c|c|c|c|c|}
\hline \multirow{2}{*}{$\begin{array}{c}\text { Sample } \\
\text { No. }\end{array}$} & \multicolumn{2}{|c|}{ Alanine } & \multicolumn{2}{|c|}{ Proline } & \multicolumn{2}{|c|}{ Serine } & \multicolumn{2}{|c|}{ Glutamate } & \multicolumn{2}{|c|}{ Aspartate } \\
\hline & $\mathrm{D}$ & $\% \mathrm{D}$ & $\mathrm{D}$ & $\% \mathrm{D}$ & $\mathrm{D}$ & $\% \mathrm{D}$ & $\mathrm{D}$ & $\% \mathrm{D}$ & D & $\% \mathrm{D}$ \\
\hline $1 \mathrm{~B}$ & $\begin{array}{c}46.3 \\
(36.7-56.0)\end{array}$ & $\begin{array}{c}44.7 \\
(43.5-46.0)\end{array}$ & $\begin{array}{c}1.1 \\
(0.9-1.3)\end{array}$ & $\begin{array}{c}3.7 \\
(3.5-3.8)\end{array}$ & $\begin{array}{c}1.3 \\
(0.7-1.9)\end{array}$ & $\begin{array}{c}14.3 \\
(12.9-15.7)\end{array}$ & $\begin{array}{c}8.8 \\
(3.4-14.3)\end{array}$ & $\begin{array}{c}7.7 \\
(6.4-9.1)\end{array}$ & $\begin{array}{c}0.2 \\
(0.1-0.3)\end{array}$ & $\begin{array}{c}6.7 \\
(3.1-10.4)\end{array}$ \\
\hline 12 & $\begin{array}{c}39.9 \\
(38.0-41.8)\end{array}$ & $\begin{array}{c}45.9 \\
(43.6-48.1)\end{array}$ & $\begin{array}{c}1.4 \\
(1.3-1.5)\end{array}$ & $\begin{array}{c}4.8 \\
(4.2-5.4)\end{array}$ & $\begin{array}{c}1.3 \\
(1.2-1.4)\end{array}$ & $\begin{array}{c}13.0 \\
(12.0-13.9)\end{array}$ & $\begin{array}{c}12.0 \\
(11.1-13.0)\end{array}$ & $\begin{array}{c}10.3 \\
(10.1-10.5)\end{array}$ & $\begin{array}{c}0.2 \\
(0.2-0.3)\end{array}$ & $\begin{array}{c}6.0 \\
(5.9-6.2)\end{array}$ \\
\hline $2 \mathrm{~A}$ & $\begin{array}{c}38.4 \\
(27.9-49.0)\end{array}$ & $\begin{array}{c}56.8 \\
(56.0-57.7)\end{array}$ & $\begin{array}{c}0.6 \\
(0.3-0.8)\end{array}$ & $\begin{array}{c}1.0 \\
(0.8-1.3)\end{array}$ & $\begin{array}{c}1.9 \\
(1.7-2.1)\end{array}$ & $\begin{array}{c}32.1 \\
(29.9-34.3)\end{array}$ & $\begin{array}{c}12.0 \\
(1.5-22.5)\end{array}$ & $\begin{array}{c}12.3 \\
(10.4-14.3)\end{array}$ & $\begin{array}{c}0.2 \\
(0.1-0.4)\end{array}$ & $\begin{array}{c}7.9 \\
(7.3-8.5)\end{array}$ \\
\hline 26 & $\begin{array}{c}27.7 \\
(19.4-35.9)\end{array}$ & $\begin{array}{c}67.1 \\
(66.1-68.0)\end{array}$ & $\begin{array}{c}5.0 \\
(4.8-5.2)\end{array}$ & $\begin{array}{c}0.7 \\
(0.6-0.8)\end{array}$ & $\begin{array}{c}1.0 \\
(0.6-1.3)\end{array}$ & $\begin{array}{c}10.4 \\
(8.9-11.9)\end{array}$ & $\begin{array}{c}2.3 \\
(2.2-2.4)\end{array}$ & $\begin{array}{c}3.9 \\
(3.2-4.6)\end{array}$ & $\begin{array}{c}0.10 \\
(0.06-0.14)\end{array}$ & $\begin{array}{c}3.4 \\
(2.0-4.9)\end{array}$ \\
\hline 30 & $\begin{array}{c}84.2 \\
(70.7-97.7)\end{array}$ & $\begin{array}{c}44.5 \\
(44.1-44.8)\end{array}$ & $\begin{array}{c}0.8 \\
(0.7-0.8)\end{array}$ & $\begin{array}{c}1.9 \\
(1.8-2.0)\end{array}$ & $\begin{array}{c}2.47 \\
(2.46-2.49)\end{array}$ & $\begin{array}{c}12.9 \\
(11.7-14.1)\end{array}$ & $\begin{array}{c}131.1 \\
(121.9-140.2)\end{array}$ & $\begin{array}{c}49.4 \\
(49.2-49.6)\end{array}$ & $\begin{array}{c}47.0 \\
(45.3-48.6)\end{array}$ & $\begin{array}{c}66.5 \\
(62.0-71.0)\end{array}$ \\
\hline 7 & $\begin{array}{c}108.3 \\
(87.1-129.5)\end{array}$ & $\begin{array}{c}46.5 \\
(43.5-49.5)\end{array}$ & $\begin{array}{c}1.1 \\
(0.9-1.2)\end{array}$ & $\begin{array}{c}2.2 \\
(2.2-2.3)\end{array}$ & $\begin{array}{c}3.0 \\
(2.7-3.3)\end{array}$ & $\begin{array}{c}17.3 \\
(15.7-18.8)\end{array}$ & $\begin{array}{c}207.8 \\
(164.5-251.0)\end{array}$ & $\begin{array}{c}49.5 \\
(48.8-50.1)\end{array}$ & $\begin{array}{c}52.7 \\
(35.6-69.8)\end{array}$ & $\begin{array}{c}73.5 \\
(71.7-75.4)\end{array}$ \\
\hline 15 & $\begin{array}{c}67.2 \\
(61.4-72.9)\end{array}$ & $\begin{array}{c}42.6 \\
(42.2-43.1)\end{array}$ & $\begin{array}{c}0.6 \\
(0.5-0.8)\end{array}$ & $\begin{array}{c}1.7 \\
(1.7-1.8)\end{array}$ & $\begin{array}{c}2.0 \\
(1.5-2.6)\end{array}$ & $\begin{array}{c}14.8 \\
(12.8-16.8)\end{array}$ & $\begin{array}{c}48.3 \\
(28.8-67.7)\end{array}$ & $\begin{array}{c}39.6 \\
(35.3-43.9)\end{array}$ & $\begin{array}{c}25.1 \\
(10.6-39.6)\end{array}$ & $\begin{array}{c}71.6 \\
(64.1-79.1)\end{array}$ \\
\hline $5 B$ & $\begin{array}{c}18.5 \\
(15.3-21.6)\end{array}$ & $\begin{array}{c}45.7 \\
(43.6-47.8)\end{array}$ & $\begin{array}{c}1.1 \\
(1.0-1.2)\end{array}$ & $\begin{array}{c}0.8 \\
(0.7-0.8)\end{array}$ & $\begin{array}{c}0.2 \\
(0.2-0.3)\end{array}$ & $\begin{array}{c}9.3 \\
(8.7-9.9)\end{array}$ & $\begin{array}{c}3.5 \\
(2.3-4.6)\end{array}$ & $\begin{array}{c}17.7 \\
(17.6-17.9)\end{array}$ & $\begin{array}{c}0.7 \\
(0.4-0.9)\end{array}$ & $\begin{array}{c}34.9 \\
(23.5-46.3)\end{array}$ \\
\hline
\end{tabular}

* Values are shown in the format of average (range) $(\mathrm{n}=2)$.

\section{Discussion}

In this study, we isolated 38 bacterial strains from rat intestine and profiled in vitro production of free D-AAs, with a focus on D-Ala. The main sources of D-Ala in mammals are currently recognized as diet and gut microbiota (28). Significantly higher levels of D-Ala, together with D-Asp, D-Glu, and D-Pro, were detected in the rodent intestinal content with a normal gut microbiota relative to GF animals (20, 29). More importantly, the bioinformatic analysis suggested D-Ala production was associated with certain taxa in intestinal microbiota (29), but to the best of our knowledge, no experimental evidence has been ever reported. The advance in strain typing by MALDI-TOF MS has made it straightforward to rapidly distinguish different microbial species and strains based on distinct proteomic signatures in mass spectra. From more than 600 microbial colonies, 38 bacterial strains belonging to 11 species and four genres were rapidly isolated from rat intestine (Figure 1). All isolates were assigned to the Firmicutes phylum. Such limited taxonomic diversity was likely due to the use of only one medium and may be improved by screening more cultivation conditions. Nonetheless, Firmicutes comprises the majority $(>78 \%)$ of microbial taxa in the rat digestive tract (30). Also, previous studies found that the relative abundance of Firmicutes showed the highest correlation with free D-AA levels in colonic lumen among commensal microbial taxa in mice (29). Indeed, 19 out of 38 isolated strains were confirmed as D-AA producers via the DAAO assay under our experimental conditions (Figure 2). Substantial inter- and intra-species variations in the free D-AA types and levels were observed (Figure 4 and Table 2), which is otherwise challenging to discover using culture-free methods such as metagenomic 16S rRNA sequencing. 
A range of analytical techniques have been used to detect D-Ala in biological samples (31). To quantify secreted D-Ala in monoclonal cultures derived from rat gut microbiota, we first utilized an enzymatic assay that performs oxidative deamination of D-Ala followed by spectrophotometric detection of hydrogen peroxide as a reaction product (32). The absolute stereoselectivity of DAAO allowed high-throughput profiling of D-Ala content in complex matrices, such as microbial crude extracts using microtiter plates. However, due to the broad substrate range of DAAO towards neutral D-AAs, analytical modalities with improved molecular selectivity are necessary to separate and detect different D-AAs. For the top D-Ala producers determined by the DAAO assay, we applied chiral LC-MS/MS to quantify D-Ala, D-Pro, D-Ser, D-Glu, and D-Asp in their extracellular extracts. When compared with enzymatic assays, the analytical throughput of LC-MS/MS was much lower because of the use of SPE cleanup, derivatization, and chromatographic separation, but new insights were revealed due to the enhanced molecular resolution. The amount of D-Ala correlated well between the DAAO and LC-MS/MS results, while D-Ser and D-Pro were low but non-negligible (Table 2). In addition, poor DAAO substrates, including acidic D-Glu and D-Asp, were detected using LC-MS/MS. Future enzymatic screening experiments can benefit from including DAAOs with complementary substrate scopes, such as D-Asp oxidase, which reacts with D-Glu and D-Asp, to improve the molecular coverage of enzymatic assays.

Both enzymatic measurement and LC-MS/MS quantification on D-AA levels (Figure 2, Table 2, and Figure 4) showed the inter- and intra-species variations of the amount and composition of D-AAs secreted by bacteria. While Ala and Glu racemases are ubiquitous in bacterial species for cell wall peptidoglycan synthesis, other AA racemases have been found in different bacterial species (33). Previous research showed that there is a large diversity in the phylogenetic distribution of AA racemases and in the composition and amount of D-AA released by bacteria, mostly on the genus level $(23,34)$. Our results further show that such variation in D-AA secretion exists within the same genus and even the same species. Intra-species diversity in the form of haplotypes within bacterial strains of the same species in the human microbiome has been reported (35), and such genetic variations can affect the phenotype of microbial strains, including metabolite production. Thus, chemical characterization of bacterial metabolites is necessary to predict the production of D-AAs as bacterial metabolites, as well as deeper analysis of the microbial genome. Interestingly, looking at $B$. cereus and $B$. amyloliquefaciens, we noticed that different strains of the same species can produce different total levels of DAAs while keeping the ratios of D-Ala and D-Glu similar within the same species (Table 2 and Figure 4). The similar ratios of D-Ala and D-Glu may imply a synergistic and constitutive expression of Ala and Glu racemases in the species investigated, as previous work has reported constitutive expression of these two racemases in Mycobacterium $(36,37)$. These different levels of secreted D-AAs may also be related to a variety of bacterial metabolite secretion mechanisms (38).

Among all five D-AAs being measured, our results showed that D-Ala and D-Glu were among the highest levels (Figure 4). This is not surprising, as D-Ala is an essential component of the peptidoglycans in bacterial cell wall structures. D-Ala also plays role in the assembly of teichoic acids in the cell walls of Gram-positive bacteria (39). The D-alanylation of teichoic acids was found to be strongly related to the pathogenicity of Gram- 
positive bacteria and host immune responses $(40,41)$. For some Bacillus species, D-Ala and Ala racemase activities were found to suppress germination during spore development $(42,43)$. The eight highest D-AA producers we measured using LC-MS/MS are all Bacillus species and secrete noticeable amounts of D-Ala. This seems to contradict the results from Lam et al. (23) where no D-Ala was detected in the supernatant of a $B$. subtilis culture. However, we also noticed that even within the same species, some strains do not secrete D-AAs at all, whereas others are high D-AA producers (Figure 2). This again shows the importance of chemical phenotyping to capture bacterial intraspecies variation within the microbiota.

In addition to D-Ala, numerous Gram-positive and Gram-negative bacteria, including B. subtilis, produce D-Glu via Glu racemase $(17,23,44)$. In our study, in contrast to D-Ala, which had a more consistent ratio throughout all Bacillus species, the amounts of D-Glu varied in both terms of percentage and absolute concentration. More specifically, high levels of D-Glu were secreted from B. cereus compared to other Bacillus species (Table 2 and Figure 4). The separate studies of Fox et al. (45), Leoff et al. (46), and Choudhury et al. (47) reported potential differences in bacterial cell wall architecture in different Bacillus species. It is thus possible that B. cereus putatively has a different cell wall composition of D-Glu than other Bacillus species. The differences in D-Glu composition among Bacillus species could be the result of a species-specific Glu racemase. For example, B. subtilis has RacE and YrpC as the two Glu racemases, while B. anthracis contains RacE1 and RacE2 (48). Since the steady-state kinetic parameters of these racemases differ (48), the formation of D-Glu will vary among the bacterial species as a result.

The pattern of elevated D-AAs in B. cereus also applied to D-Asp, another acidic D-AA. In B. cereus, both high absolute concentrations and ratios of D-Asp were observed, while the D-Asp amount was relatively lower in other species (Table 2 and Figure 4). The recent study by Kajitani et al. (49) reported enzymatic screening for D-Asp-producing lactic acid bacteria from food sources. Interestingly, their findings aligned with our current study in that the amounts of D-Asp varied among different strains of the same species. Our results further show that the gut microbiome's ability to produce and secrete D-AAs is strain-dependent. The amounts of D-Ser and D-Pro, other DAAO substrates, remained relatively low but non-negligible regardless of species and strains (Table 2 and Figure 4). Unique to bacteria, the Ser/Ala racemase activity of VanT exchanges D-Ala with D-Ser for resistance against bactericidal agents like vancomycin (50). Some bacteria include the minor DAAs for their peptidoglycan composition (51-54). Although Pro racemase was identified in Clostridium difficile and Clostridium sticklandii, the incorporation of D-Pro in peptidoglycan remains unknown (17).

The secretion of D-AAs from bacterial species is implicated in regulating microbial communities and in modifying host responses. In microbial communities, exogenous D-AAs secreted by D-AA producers may be modulators of microbial adaptation to the environment and microbial diversity $(23,55)$. D-AAs can induce host responses via interaction with mucosal or airway surfaces $(20,21,34)$. The gut microbiota-produced free D-AAs can also be absorbed through the gut and potentially regulate host physiology. Unlike D-Ser and D-Asp, which originate from endogenous biosynthesis in addition to microbiota and diet, the main source of intestinal D-Ala, D-Glu, and D-Pro in mammals is the gut microbiota $(18,20)$. Though the mechanisms of transport and 
metabolism of free D-AAs in hosts are poorly understood, results of previous studies, including our own, indicated that D-Ala may be involved in animal behavior and glucose metabolism $(14,56)$. A more detailed summary of the implications of D-Ala in hosts can be found in the recent review by Lee et al. (28). While D-Glu and D-Pro are produced by the gut microbiota strains, the roles of these two D-AAs in animals remain obscure, although recent studies suggest protective roles for D-Glu against Alzheimer's Disease (57-61), and sedative and hypnotic effects of D-Pro in neonatal chicks (62). We also found low but non-negligible amounts of D-Ser and D-Asp (except for B. cereus) in the gut microbial strains. The physiological roles of D-Ser and D-Asp have been extensively studied in the central nervous system (CNS) $(61,63)$ and endocrine system $(63,64)$. Although the biological roles of gut microbiota-derived D-Ser and D-Asp in the host are equivocal, putative functions of gut microbiota- or diet-derived D-Ser in the CNS $(65,66)$ and acute kidney injury (67) have been reported. An increase in D-Ser, as well as D-Asp, in some brain regions of GF mice compared to normal mice also reflects the effect of gut microbiota on the metabolism of D-AAs in the host (68). In general, the physiological and pathophysiological implications of these microbiota-associated D-AAs in hosts remain obscure and warrant further study.

\section{Conclusions}

Gut microbiota produce a range of diverse compounds that affect host CNS function, immunity, and metabolism. A number of research studies highlight the importance of one of those gut-derived compounds, the D-AAs, in various signal pathways in hosts and thus, their therapeutic potentials. Here, we describe an analytical approach to isolate gut microbial species and determine their D-AA production via a combination of DAAO enzymatic assay and LC-MS/MS. We observed strain-specific D-AA production where the absolute concentrations of DAAs varied, despite the percentage of some D-AAs remaining constant regardless of bacterial strain or species. Our work demonstrates that the chemical phenotyping of gut microbial strains is necessary to reveal the intraand inter-species differences in metabolite production, which is otherwise challenging to discover using microbiome sequencing methods. As different strains of bacterial species can induce different host responses (69), it is important to characterize the unique D-AA production profiles from the gut bacterial strains to better understand the physiological and pathophysiological implications of strain-specific D-AAs on the host.

\section{Experimental procedures}

\section{Materials and chemicals}

Materials and chemicals were purchased from Sigma-Aldrich or Fisher Scientific, unless noted otherwise.

\section{Microbial isolation from rat intestine}

Vertebrate animal use was approved by the Institutional Animal Care and Use Committee, University of Illinois at Urbana-Champaign, and in full compliance with federal guidelines for the humane care and treatment of 
animals. Three adult male (3-4 months old) Sprague-Dawley rats (Harlan Laboratories) were decapitated by a sharp guillotine. Fresh intestines, surgically removed and containing digesta samples, were homogenized to a final concentration of $0.1 \mathrm{~g} / \mathrm{mL}$ in iced PBS-R buffer $(1 \mathrm{mg} / \mathrm{mL}$ ascorbic acid, $60 \mu \mathrm{g} / \mathrm{mL}$ uric acid, $100 \mu \mathrm{g} / \mathrm{mL}$ L-glutathione, $20 \%$ glycerol in PBS). Cell suspensions in ten-fold serial dilutions $\left(10^{0}-10^{-6}\right)$ were plated on Rmedium agar plates $\left(28.4 \mathrm{mg} / \mathrm{mL} \mathrm{BD} \mathrm{BBL}^{\mathrm{TM}}\right.$ Schaedler Broth, $1 \mathrm{mg} / \mathrm{mL}$ ascorbic acid, $400 \mu \mathrm{g} / \mathrm{mL}$ uric acid, 100 $\mu \mathrm{g} / \mathrm{mL}$ L-glutathione, $15.0 \mathrm{~g} / \mathrm{L}$ agar) and incubated at $37{ }^{\circ} \mathrm{C}$ for $24-48 \mathrm{~h}$. Colonies were re-streaked three times for clonal purification. For subsequent analyses, cells were spread on the R-medium agar as lawns, collected using a cotton swab, and transferred to solutions by soaking. Strains were stored as frozen stocks at $-80{ }^{\circ} \mathrm{C}$ in $\mathrm{R}$ medium supplemented with $15 \%(v / v)$ glycerol until analysis.

\section{Strain typing using MALDI-TOF MS}

For strain typing, a small portion of a single colony was smeared as a thin film onto a Bruker MALDI Biotarget 384 sample spot by pipet tips. Each deposit was immediately overlaid with $1 \mu \mathrm{L}$ of matrix solution $(10 \mathrm{mg} / \mathrm{mL}$ $\alpha$-Cyano-4-hydroxycinnamic acid (HCCA) in 50:47.5:2.5 acetonitrile (ACN): $\mathrm{ddH}_{2} \mathrm{O}: \mathrm{TFA}$ ) and air dried. To add the MALDI mass spectra of newly isolated microbes to the Bruker Taxonomy database, about $10 \mathrm{mg}$ of biomass recovered from the frozen stocks were first washed using $300 \mu \mathrm{L}$ of $\mathrm{ddH}_{2} \mathrm{O}$ followed by $900 \mu \mathrm{L}$ of ethanol. Samples were then lysed with $80 \mu \mathrm{L}$ of $70 \%$ formic acid (FA) followed by $80 \mu \mathrm{L}$ of ACN. After centrifugation, $1 \mu \mathrm{L}$ of supernatant was spotted onto a Bruker MALDI Biotarget 384 sample spot, immediately overlaid with 1 $\mu \mathrm{L}$ of HCCA matrix solution, and air dried. Mass spectra were collected using a Bruker autoflex maX LRF mass spectrometer, following recommended instrumental settings by the Bruker MALDI Biotyper Main Spectrum Peak identification standard method (mass range: 2,000 to 20,000 Da; linear positive method; laser frequency at $60 \mathrm{~Hz}$ ). Strain typing was performed using the Bruker MALDI Biotyper software, version 4.0, by pattern matching between collected spectra and the reference spectra in the Bruker Taxonomy database. A spectra clustering graph of select 38 rat gut microbes was generated using the Biotyper software, and the spectra of closely related species and E. coli DH5alpha in the Bruker Taxonomy database were included as references and as an outgroup, respectively. From the graphic output, the correlation distances measured were obtained using the TreeSnatcher Plus software (70) to redraw the Class dendrogram using the MEGA-X software (71) (Figure 1).

\section{Strain typing using 16S rRNA gene sequencing}

To isolate genomic DNA from microbial cultures, fresh agar cultures were resuspended in $100 \mu \mathrm{L}$ of digestion buffer (10 mM Tris-HCl, $50 \mathrm{mM}$ EDTA, $\mathrm{pH} 7.0$ at $\left.25^{\circ} \mathrm{C}\right)$, supplemented with $5 \mu \mathrm{L}$ of $10 \mathrm{mg} / \mathrm{mL}$ lysozyme (10 $\mathrm{mM}$ Tris-HCl, $\mathrm{pH} 7.0$, at $25^{\circ} \mathrm{C}, 50 \%$ glycerol) and $5 \mu \mathrm{L}$ of $20 \mathrm{mg} / \mathrm{mL}$ proteinase $\mathrm{K}(10 \mathrm{mM}$ Tris- $\mathrm{HCl}, \mathrm{pH} 7.0$ at $25^{\circ} \mathrm{C}, 50 \%$ glycerol), and incubated at $37^{\circ} \mathrm{C}$ for $1 \mathrm{~h}$. Genomic DNA was then isolated using the Wizard Genomic DNA Purification Kit (Promega) following the manufacturer's instructions. The 16S RNA gene sequences were 
PCR amplified from genomic DNA by PrimeSTAR Max DNA polymerase (Takara) using the 27F (5'AGAGTTTGATCCTGGCTCAG-3') and 1492R (5'-GGTTACCTTGTTACGACTT-3') primers. The 16S rRNA gene sequences were obtained by Sanger sequencing, processed using the Geneious Primer software (https://www.geneious.com), and analyzed using BLAST (https://blast.ncbi.nlm.nih.gov/Blast.cgi). A sequence identity cutoff of $>98.7 \%$ was adopted as an acceptable probability for identification at the species level. The phylogeny of isolates was determined by calculating evolutionary distances to close neighbors using the MEGA$\mathrm{X}$ software (Figure 2).

\section{Sample collection of D-AA secretion from microbial isolates}

For each strain, biomass collected on Day 3 was scraped from the agar and resuspended in $500 \mu \mathrm{L}$ methanol supplemented with $0.1 \%$ TFA. The organic phase was collected after centrifugation at $16,300 \times g$ for 1 min, and then $500 \mu \mathrm{L}$ of $\mathrm{ddH}_{2} \mathrm{O}$ supplemented with $0.1 \%$ TFA was added to the remaining biomass. Aqueous supernatant was collected after centrifugation at $16,300 \times g$ for $1 \mathrm{~min}$ and combined with the organic phase. Aliquots were dried under a constant flow of $\mathrm{N}_{2}$ gas and stored at $-80{ }^{\circ} \mathrm{C}$ until analysis.

\section{Enzyme assay for D-AA quantification}

The D-AA content was determined using a DAAO from porcine kidney (Sigma) coupled with a fluorometric hydrogen peroxide detection kit (Sigma, Catalog\# MAK165). D-Ala standard solutions at final concentrations of $300,100,30,10,3$, and $1 \mu \mathrm{M}$ were prepared from a $100 \mathrm{mM}$ stock solution. A series of hydrogen peroxide standard solutions with the same concentrations as the D-Ala standards were prepared from 3\% stock solution. Dried microbial secretes were thawed and reconstituted in $400 \mu \mathrm{L}$ of the provided assay buffer. A $10 \times$ dilution of each sample was also prepared. Measurement was carried out in technical duplicates. The reactions were initiated by adding $5 \mu \mathrm{L}$ of DAAO, and fluorescence readings with $540 \mathrm{~nm}$ excitation and 590 emission were taken at indicated time intervals.

\section{LC-MS/MS for DAA quantification}

For chiral LC-MS/MS analysis, microbial samples were first processed using SCX-SPE. One milliliter of crude, extracellular microbial extracts was reconstituted in 50:50 methanol: $\mathrm{ddH}_{2} \mathrm{O}$ (pH was adjusted to 2 2.5 using 10 mM FA) before being loaded onto Discovery $60 \mathrm{mg}$ DSC-SCX SPE columns (Waters). Columns were conditioned and washed using $2 \mathrm{~mL}$ of $200 \mathrm{mM}$ FA in 50:50 methanol: $\mathrm{ddH}_{2} \mathrm{O}(\mathrm{pH} 2$ 2.5) before and after sample loading, respectively. AA content was eluted using $2 \mathrm{~mL}$ of $3 \mathrm{M} \mathrm{NH}_{4} \mathrm{OH}$ in 50:50 methanol: $\mathrm{ddH}_{2} \mathrm{O}$ and dried in a SpeedVac (ThermoFisher). Each elute was then reconstituted in $500 \mu \mathrm{L}$ of $\mathrm{ddH}_{2} \mathrm{O}$ and processed using a 0.22 $\mu \mathrm{M}$ centrifugal filter. Each $20 \mu \mathrm{L}$ sample aliquot was dried in a SpeedVac and reconstituted in $0.5 \mathrm{M}$ sodium bicarbonate solution. The sample or standard was mixed with $\mathrm{N} \alpha$-(2,4-Dinitro-5-fluorophenyl)-L-valinamide (1 $\mathrm{mg} / \mathrm{mL}$ in $\mathrm{ACN}$ ), a modified Marfey's reagent, in a 1:1 ratio. The reaction mixture was incubated in an oven at 
$60{ }^{\circ} \mathrm{C}$ for $3 \mathrm{~h}$. Following derivatization, the sample reaction mixture was diluted 20 -fold in $95 \% \mathrm{LC}$ mobile phase A/ACN and analyzed by LC-MS/MS. Chiral separations were performed using a Bruker EVOQ Elite Triple Quadrupole mass spectrometer coupled with an Elute UHPLC module. A reversed-phase Kinetex phenyl-hexyl HPLC column - $2.6 \mu \mathrm{m}$ particle size, $100 \AA$ pore size, $100 \mathrm{~mm}$ (length) $\times 2.1 \mathrm{~mm}$ inner diameter (Phenomenex) - was used for the separation of enantiomers. A gradient method was developed using mobile phase A, $25 \mathrm{mM}$ ammonium formate; mobile phase $\mathrm{B}$, methanol; flow rate, $300 \mu \mathrm{L} / \mathrm{min}$. The mass spectrometer equipped with an electrospray ionization source was operated under the following conditions: spray voltage for negative mode, $-3500 \mathrm{~V}$; cone temperature, $250{ }^{\circ} \mathrm{C}$; cone gas flow, 20; heated probe temperature, $400{ }^{\circ} \mathrm{C}$; probe gas flow, 45 ; nebulizer gas flow, 50. Each analyte retention time and fragmentation parameter was established from the corresponding derivatized standard. The resulting chromatograms were analyzed by Data Reviewer 8 (Bruker Corp.). Protein quantification was performed using the Pierce BCA Protein Assay Kit. The protein levels were used to adjust samples for different sizes (protein amounts) to allow D-AA level comparison between the strains.

\section{Data availability}

All processed data supporting the conclusions are presented in the main text and Supporting Information. All original data are available and can be shared upon request by contacting the corresponding authors.

Supporting information-This article contains supporting information.

Author contributions- Cindy J. Lee: Writing-Original Draft, Investigation, Formal analysis, Tian A. Qiu: Writing-Original Draft, Investigation, Zhilai Hong: Writing-Original Draft, Investigation, Zhenkun Zhang: Investigation, Yuhao Min: Investigation, Linzixuan Zhang: Investigation, Lei Dai: Formal analysis, Huimin Zhao: Supervision, Tong Si: Writing-Original Draft, Investigation, Conceptualization, Writing-Review \& Editing, Jonathan V. Sweedler: Supervision, Conceptualization. Writing-Review \& Editing

Funding-The authors gratefully acknowledge support by the American Diabetes Association Pathway to Stop Diabetes Grant No. 1-18-VSN-19. T.A.Q. acknowledges support by a Beckman Institute Postdoctoral Fellowship, funded by a Beckman Foundation gift to the Beckman Institute for Advanced Science and Technology at the University of Illinois at Urbana-Champaign. T.S. acknowledges a postdoctoral fellowship support from the Carl R. Woese Institute for Genomic Biology (UIUC). We thank Stanislav S. Rubakhin and Joanna F. Ellis for their help with animal experiments.

Conflict of interest-The authors declare that they have no conflicts of interest with the contents of this article.

Abbreviations - The abbreviations used are: AAs, amino acids; ACN, acetonitrile; Ala, alanine; Asp, aspartate; CNS, central nervous system; D-AA, D-amino acid; DAAO, D-amino acid oxidase; D-Ala, D-alanine; D-Ala, D- 
alanine; D-Asp, D-aspartate; D-Glu, D-glutamate; D-Pro, D-proline; D-Ser, D-serine; FA, formic acid; Glu, glutamate; HCCA , $\alpha$-Cyano-4-hydroxycinnamic acid; L-AAs, L-amino acids; NMDAR, N-methyl-d-aspartate receptor; Pro, proline; SCX, strong cation exchange; Ser, serine; SPE, solid phase extraction; T2D, type 2 diabetes

\section{References}

1. Liu, Y., Hou, Y., Wang, G., Zheng, X., and Hao, H. (2020) Gut Microbial Metabolites of Aromatic Amino Acids as Signals in Host-Microbe Interplay. Trends Endocrinol. Metab. 31, 818-834

2. Koh, A., De Vadder, F., Kovatcheva-Datchary, P., and Bäckhed, F. (2016) From Dietary Fiber to Host Physiology: Short-Chain Fatty Acids as Key Bacterial Metabolites. Cell 165, 1332-1345

3. Rastelli, M., Cani, P. D., and Knauf, C. (2019) The Gut Microbiome Influences Host Endocrine Functions. Endocr. Rev. 40, 1271-1284

4. Strandwitz, P. (2018) Neurotransmitter modulation by the gut microbiota. Brain Res. 1693, 128133

5. Ishii, C., Furusho, A., Hsieh, C.-L., and Hamase, K. (2020) Multi-Dimensional High-Performance Liquid Chromatographic Determination of Chiral Amino Acids and Related Compounds in Real World Samples. Chromatography 41, 1-17

6. Wolosker, H., Dumin, E., Balan, L., and Foltyn, V. N. (2008) D-amino acids in the brain: D-serine in neurotransmission and neurodegeneration. FEBS J. 275, 3514-3526

7. Lockridge, A. D., Baumann, D. C., Akhaphong, B., Abrenica, A., Miller, R. F., and Alejandro, E. U. (2016) Serine racemase is expressed in islets and contributes to the regulation of glucose homeostasis. Islets 8, 195-206

8. Mothet, J.-P., Le Bail, M., and Billard, J.-M. (2015) Time and space profiling of NMDA receptor co-agonist functions. J. Neurochem. 135, 210-225

9. D'Aniello, A., Di Fiore, M. M., Fisher, G. H., Milone, A., Seleni, A., D'Aniello, S., Perna, A. F., and Ingrosso, D. (2000) Occurrence of D-aspartic acid and N-methyl-D-aspartic acid in rat neuroendocrine tissues and their role in the modulation of luteinizing hormone and growth hormone release. FASEB J. 14, 699-714

10. Furuchi, T., and Homma, H. (2005) Free D-aspartate in mammals. Biol. Pharm. Bull. 28, 15661570

11. Roshanzamir, F., and Safavi, S. M. (2017) The putative effects of D-Aspartic acid on blood testosterone levels: A systematic review. Int. J. Reprod. Biomed. 15, 1-10

12. Morikawa, A., Hamase, K., Ohgusu, T., Etoh, S., Tanaka, H., Koshiishi, I., Shoyama, Y., and Zaitsu, K. (2007) Immunohistochemical localization of D-alanine to beta-cells in rat pancreas. Biochem. Biophys. Res. Commun. 355, 872-876 
13. Etoh, S., Hamase, K., Morikawa, A., Ohgusu, T., and Zaitsu, K. (2009) Enantioselective visualization of D-alanine in rat anterior pituitary gland: localization to ACTH-secreting cells. Anal. Bioanal. Chem. 393, 217-223

14. Ota, N., Rubakhin, S. S., and Sweedler, J. V. (2014) D-Alanine in the islets of Langerhans of rat pancreas. Biochem. Biophys. Res. Commun. 447, 328-333

15. Wang, L., Ota, N., Romanova, E. V., and Sweedler, J. V. (2011) A novel pyridoxal 5'-phosphatedependent amino acid racemase in the Aplysia californica central nervous system. J. Biol. Chem. 286, $13765-13774$

16. Kim, P. M., Duan, X., Huang, A. S., Liu, C. Y., Ming, G.-1., Song, H., and Snyder, S. H. (2010) Aspartate racemase, generating neuronal D-aspartate, regulates adult neurogenesis. Proc. Natl. Acad. Sci. U. S. A. 107, 3175-3179

17. Cava, F., Lam, H., de Pedro, M. A., and Waldor, M. K. (2011) Emerging knowledge of regulatory roles of d-amino acids in bacteria. Cell. Mol. Life Sci. 68, 817-831

18. Karakawa, S., Miyoshi, Y., Konno, R., Koyanagi, S., Mita, M., Ohdo, S., and Hamase, K. (2013) Two-dimensional high-performance liquid chromatographic determination of day-night variation of D-alanine in mammals and factors controlling the circadian changes. Anal. Bioanal. Chem. 405, 8083-8091

19. Qin, J., Li, Y., Cai, Z., Li, S., Zhu, J., Zhang, F., Liang, S., Zhang, W., Guan, Y., Shen, D., Peng, Y., Zhang, D., Jie, Z., Wu, W., Qin, Y., Xue, W., Li, J., Han, L., Lu, D., Wu, P., Dai, Y., Sun, X., Li, Z., Tang, A., Zhong, S., Li, X., Chen, W., Xu, R., Wang, M., Feng, Q., Gong, M., Yu, J., Zhang, Y., Zhang, M., Hansen, T., Sanchez, G., Raes, J., Falony, G., Okuda, S., Almeida, M., LeChatelier, E., Renault, P., Pons, N., Batto, J.-M., Zhang, Z., Chen, H., Yang, R., Zheng, W., Li, S., Yang, H., Wang, J., Ehrlich, S. D., Nielsen, R., Pedersen, O., Kristiansen, K., and Wang, J. (2012) A metagenomewide association study of gut microbiota in type 2 diabetes. Nature 490, 55-60

20. Sasabe, J., Miyoshi, Y., Rakoff-Nahoum, S., Zhang, T., Mita, M., Davis, B. M., Hamase, K., and Waldor, M. K. (2016) Interplay between microbial d -amino acids and host $d$-amino acid oxidase modifies murine mucosal defence and gut microbiota. Nat. Microbiol. 1, 1-7

21. Lee, R. J., Hariri, B. M., McMahon, D. B., Chen, B., Doghramji, L., Adappa, N. D., Palmer, J. N., Kennedy, D. W., Jiang, P., Margolskee, R. F., and Cohen, N. A. (2017) Bacterial d-amino acids suppress sinonasal innate immunity through sweet taste receptors in solitary chemosensory cells. Sci. Signal. 10, eaam 7703

22. Holmes, E., Li, J. V., Marchesi, J. R., and Nicholson, J. K. (2012) Gut microbiota composition and activity in relation to host metabolic phenotype and disease risk. Cell Metab. 16, 559-564

23. Lam, H., Oh, D.-C., Cava, F., Takacs, C. N., Clardy, J., Pedro, M. A. d., and Waldor, M. K. (2009) D-Amino Acids Govern Stationary Phase Cell Wall Remodeling in Bacteria. Science 325, 15521555

24. Patnode, M. L., Guruge, J. L., Castillo, J. J., Couture, G. A., Lombard, V., Terrapon, N., Henrissat, B., Lebrilla, C. B., and Gordon, J. I. (2021) Strain-level functional variation in the human gut microbiota based on bacterial binding to artificial food particles. Cell Host Microbe 29, 664673.e665 
25. Yang, C., Mogno, I., Contijoch, E. J., Borgerding, J. N., Aggarwala, V., Li, Z., Siu, S., Grasset, E. K., Helmus, D. S., Dubinsky, M. C., Mehandru, S., Cerutti, A., and Faith, J. J. (2020) Fecal IgA Levels Are Determined by Strain-Level Differences in Bacteroides ovatus and Are Modifiable by Gut Microbiota Manipulation. Cell Host Microbe 27, 467-475.e466

26. Dione, N., Khelaifia, S., La Scola, B., Lagier, J. C., and Raoult, D. (2016) A quasi-universal medium to break the aerobic/anaerobic bacterial culture dichotomy in clinical microbiology. Clin. Microbiol. Infect. 22, 53-58

27. Yamashita, T., Ashiuchi, M., Ohnishi, K., Kato, S. i., Nagata, S., and Misono, H. (2004) Molecular identification of monomeric aspartate racemase from Bifidobacterium bifidum. Eur. J. Biochem. 271, 4798-4803

28. Lee, C. J., Qiu, T. A., and Sweedler, J. V. (2020) d-Alanine: Distribution, origin, physiological relevance, and implications in disease. Biochim. Biophys. Acta 1868, 140482

29. Matsumoto, M., Kunisawa, A., Hattori, T., Kawana, S., Kitada, Y., Tamada, H., Kawano, S., Hayakawa, Y., Iida, J., and Fukusaki, E. (2018) Free D -amino acids produced by commensal bacteria in the colonic lumen. Sci. Rep. 8, 17915

30. Li, D., Chen, H., Mao, B., Yang, Q., Zhao, J., Gu, Z., Zhang, H., Chen, Y. Q., and Chen, W. (2017) Microbial Biogeography and Core Microbiota of the Rat Digestive Tract. Sci. Rep. 8, 45840

31. Kirschner, D. L., and Green, T. K. (2009) Separation and sensitive detection of D-amino acids in biological matrices. J. Sep. Sci. 32, 2305-2318

32. Rosini, E., Caldinelli, L., and Piubelli, L. (2018) Assays of D-Amino Acid Oxidase Activity. Front. Mol. Biosci. 4, 102

33. Hernández, S. B., and Cava, F. (2016) Environmental roles of microbial amino acid racemases. Environ. Microbiol. 18, 1673-1685

34. Suzuki, M., Sujino, T., Chiba, S., Harada, Y., Goto, M., Takahashi, R., Mita, M., Hamase, K., Kanai, T., Ito, M., Waldor, M. K., Yasui, M., and Sasabe, J. (2021) Host-microbe cross-talk governs amino acid chirality to regulate survival and differentiation of B cells. Sci. Adv. 7, eabd6480

35. Kuleshov, V., Jiang, C., Zhou, W., Jahanbani, F., Batzoglou, S., and Snyder, M. (2016) Synthetic long-read sequencing reveals intraspecies diversity in the human microbiome. Nat. Biotechnol. 34, 64-69

36. Mortuza, R. (2017) Thesis: Phenotypic and Molecular Analysis of the Alanine and Glutamate Racemases of Mycobacteria, University of Otago

37. Krause, K., Poen, S., Mortuza, R., Nakatani, Y., Aung, H., Opel-Reading, H., and Cook, G. (2015) Glutamate Racemase From Mycobacterium tuberculosis: New Genetic and Structural Insights Into a Target for Antituberculosis Drug Design. Open Forum Infectious Diseases 2, doi:10.1093/ofid/ofv1133.1598

38. Krämer, R. (1994) Secretion of amino acids by bacteria: Physiology and mechanism. FEMS Microbiol. Rev. 13, 75-93 
39. Percy, M. G., and Gründling, A. (2014) Lipoteichoic Acid Synthesis and Function in Gram-Positive Bacteria. Annu. Rev. Microbiol. 68, 81-100

40. Coupri, D., Budin-Verneuil, A., Hartke, A., Benachour, A., Léger, L., Lequeux, T., Pfund, E., and Verneuil, N. (2019) Genetic and pharmacological inactivation of d-alanylation of teichoic acids sensitizes pathogenic enterococci to $\beta$-lactams. J. Antimicrob. Chemother. 74, 3162-3169

41. Chan, K. G., Mayer, M., Davis, E. M., Halperin, S. A., Lin, T.-J., and Lee, S. F. (2007) Role of dAlanylation of Streptococcus gordonii Lipoteichoic Acid in Innate and Adaptive Immunity. Infect. Immun. 75, 3033-3042

42. Chesnokova, O. N., McPherson, S. A., Steichen, C. T., and Turnbough, C. L. (2009) The SporeSpecific Alanine Racemase of Bacillus anthracis and Its Role in Suppressing Germination during Spore Development. J. Bacteriol. 191, 1303-1310

43. Preston, R. A., and Douthit, H. A. (1984) Germination of Bacillus cereus Spores: Critical Control by DL-Alanine Racemase. Microbiology 130, 3123-3133

44. Kobayashi, K., Ehrlich, S. D., Albertini, A., Amati, G., Andersen, K. K., Arnaud, M., Asai, K., Ashikaga, S., Aymerich, S., Bessieres, P., Boland, F., Brignell, S. C., Bron, S., Bunai, K., Chapuis, J., Christiansen, L. C., Danchin, A., Débarbouillé, M., Dervyn, E., Deuerling, E., Devine, K., Devine, S. K., Dreesen, O., Errington, J., Fillinger, S., Foster, S. J., Fujita, Y., Galizzi, A., Gardan, R., Eschevins, C., Fukushima, T., Haga, K., Harwood, C. R., Hecker, M., Hosoya, D., Hullo, M. F., Kakeshita, H., Karamata, D., Kasahara, Y., Kawamura, F., Koga, K., Koski, P., Kuwana, R., Imamura, D., Ishimaru, M., Ishikawa, S., Ishio, I., Coq, D. L., Masson, A., Mauël, C., Meima, R., Mellado, R. P., Moir, A., Moriya, S., Nagakawa, E., Nanamiya, H., Nakai, S., Nygaard, P., Ogura, M., Ohanan, T., O'Reilly, M., O'Rourke, M., Pragai, Z., Pooley, H. M., Rapoport, G., Rawlins, J. P., Rivas, L. A., Rivolta, C., Sadaie, A., Sadaie, Y., Sarvas, M., Sato, T., Saxild, H. H., Scanlan, E., Schumann, W., Seegers, J. F. M. L., Sekiguchi, J., Sekowska, A., Séror, S. J., Simon, M., Stragier, P., Studer, R., Takamatsu, H., Tanaka, T., Takeuchi, M., Thomaides, H. B., Vagner, V., Dijl, J. M. v., Watabe, K., Wipat, A., Yamamoto, H., Yamamoto, M., Yamamoto, Y., Yamane, K., Yata, K., Yoshida, K., Yoshikawa, H., Zuber, U., and Ogasawara, N. (2003) Essential Bacillus subtilis genes. Proc. Natl. Acad. Sci. U. S. A. 100, 4678-4683

45. Fox, A., Black, G. E., Fox, K., and Rostovtseva, S. (1993) Determination of carbohydrate profiles of Bacillus anthracis and Bacillus cereus including identification of O-methyl methylpentoses by using gas chromatography-mass spectrometry. J. Clin. Microbiol. 31, 887-894

46. Leoff, C., Saile, E., Sue, D., Wilkins, P., Quinn, C. P., Carlson, R. W., and Kannenberg, E. L. (2008) Cell Wall Carbohydrate Compositions of Strains from the Bacillus cereus Group of Species Correlate with Phylogenetic Relatedness. J. Bacteriol. 190, 112-121

47. Choudhury, B., Leoff, C., Saile, E., Wilkins, P., Quinn, C. P., Kannenberg, E. L., and Carlson, R. W. (2006) The Structure of the Major Cell Wall Polysaccharide of Bacillus anthracis Is Speciesspecific. J. Biol. Chem. 281, 27932-27941

48. Dodd, D., Reese, J. G., Louer, C. R., Ballard, J. D., Spies, M. A., and Blanke, S. R. (2007) Functional Comparison of the Two Bacillus anthracis Glutamate Racemases. J. Bacteriol. 189, $5265-5275$ 
49. Kajitani, K., Ishikawa, T., Shibata, K., Kouya, T., Kera, Y., and Takahashi, S. (2021) Development of an enzymatic screening method for d-aspartate-producing lactic acid bacteria. Enzyme Microb. Technol. 149, 109835

50. Zeng, D., Debabov, D., Hartsell, T. L., Cano, R. J., Adams, S., Schuyler, J. A., McMillan, R., and Pace, J. L. (2016) Approved Glycopeptide Antibacterial Drugs: Mechanism of Action and Resistance. Cold Spring Harb. Perspect. Med. 6, a026989

51. Reynolds, P. E., and Courvalin, P. (2005) Vancomycin Resistance in Enterococci Due to Synthesis of Precursors Terminating in d-Alanyl-d-Serine. Antimicrob. Agents Chemother. 49, 21-25

52. Sieradzki, K., and Tomasz, A. (1996) A highly vancomycin-resistant laboratory mutant of Staphylococcus aureus. FEMS Microbiol. Lett. 142, 161-166

53. Veiga, P., Piquet, S., Maisons, A., Furlan, S., Courtin, P., Chapot-Chartier, M.-P., and Kulakauskas, S. (2006) Identification of an essential gene responsible for D-Asp incorporation in the Lactococcus lactis peptidoglycan crossbridge. Mol. Microbiol. 62, 1713-1724

54. Bellais, S., Arthur, M., Dubost, L., Hugonnet, J.-E., Gutmann, L., van Heijenoort, J., Legrand, R., Brouard, J.-P., Rice, L., and Mainardi, J.-L. (2006) Aslfm, the D-aspartate ligase responsible for the addition of D-aspartic acid onto the peptidoglycan precursor of Enterococcus faecium. J. Biol. Chem. 281, 11586-11594

55. Alvarez, L., Aliashkevich, A., de Pedro, M. A., and Cava, F. (2018) Bacterial secretion of Darginine controls environmental microbial biodiversity. ISME J. 12, 438-450

56. Saitoh, Y., Katane, M., Miyamoto, T., Sekine, M., Sakai-Kato, K., and Homma, H. (2020) d-Serine and d-Alanine Regulate Adaptive Foraging Behavior in Caenorhabditis elegans via the NMDA Receptor. J. Neurosci. 40, 7531-7544

57. Lin, C.-H., Yang, H.-T., Chiu, C.-C., and Lane, H.-Y. (2017) Blood levels of D-amino acid oxidase vs. D-amino acids in reflecting cognitive aging. Sci. Rep. 7, 14849

58. Lin, C.-H., Yang, H.-T., and Lane, H.-Y. (2019) D-glutamate, D-serine, and D-alanine differ in their roles in cognitive decline in patients with Alzheimer's disease or mild cognitive impairment. Pharmacol. Biochem. Behav. 185, 172760

59. Chang, C.-H., Lin, C.-H., Liu, C.-Y., Huang, C.-S., Chen, S.-J., Lin, W.-C., Yang, H.-T., and Lane, H.-Y. (2021) Plasma d-glutamate levels for detecting mild cognitive impairment and Alzheimer's disease: Machine learning approaches. J. Psychopharm. 35, 265-272

60. Wong, D., Atiya, S., Fogarty, J., Montero-Odasso, M., Pasternak, S. H., Brymer, C., Borrie, M. J., and Bartha, R. (2020) Reduced Hippocampal Glutamate and Posterior Cingulate N-Acetyl Aspartate in Mild Cognitive Impairment and Alzheimer's Disease Is Associated with Episodic Memory Performance and White Matter Integrity in the Cingulum: A Pilot Study. J. Alzheimer's Dis. 73, 1385-1405

61. Seckler, J. M., and Lewis, S. J. (2020) Advances in D-Amino Acids in Neurological Research. Int. J. Mol. Sci. 21, 7325 
62. Hamasu, K., Shigemi, K., Tsuneyoshi, Y., Yamane, H., Sato, H., Denbow, D. M., and Furuse, M. (2010) Intracerebroventricular injection of L-proline and D-proline induces sedative and hypnotic effects by different mechanisms under an acute stressful condition in chicks. Amino Acids 38, 5764

63. Kiriyama, Y., and Nochi, H. (2016) D-Amino Acids in the Nervous and Endocrine Systems. Scientifica 2016, 6494621

64. Chieffi Baccari, G., Falvo, S., Santillo, A., Di Giacomo Russo, F., and Di Fiore, M. M. (2020) dAmino acids in mammalian endocrine tissues. Amino Acids 52, 1263-1273

65. Horio, M., Kohno, M., Fujita, Y., Ishima, T., Inoue, R., Mori, H., and Hashimoto, K. (2011) Levels of D-serine in the brain and peripheral organs of serine racemase (Srr) knock-out mice. Neurochem. Int. 59, 853-859

66. Savignac, H. M., Corona, G., Mills, H., Chen, L., Spencer, J. P. E., Tzortzis, G., and Burnet, P. W. J. (2013) Prebiotic feeding elevates central brain derived neurotrophic factor, N-methyl-d-aspartate receptor subunits and d-serine. Neurochem. Int. 63, 756-764

67. Nakade, Y., Iwata, Y., Furuichi, K., Mita, M., Hamase, K., Konno, R., Miyake, T., Sakai, N., Kitajima, S., Toyama, T., Shinozaki, Y., Sagara, A., Miyagawa, T., Hara, A., Shimizu, M., Kamikawa, Y., Sato, K., Oshima, M., Yoneda-Nakagawa, S., Yamamura, Y., Kaneko, S., Miyamoto, T., Katane, M., Homma, H., Morita, H., Suda, W., Hattori, M., and Wada, T. (2018) Gut microbiotaderived D-serine protects against acute kidney injury. JCI Insight 3, e97957

68. Kawase, T., Nagasawa, M., Ikeda, H., Yasuo, S., Koga, Y., and Furuse, M. (2017) Gut microbiota of mice putatively modifies amino acid metabolism in the host brain. Br. J. Nutr. 117, 775-783

69. Sela, U., Euler, C. W., Rosa, J. C. d., and Fischetti, V. A. (2018) Strains of bacterial species induce a greatly varied acute adaptive immune response: The contribution of the accessory genome. PLOS Pathogens 14, e1006726

70. Laubach, T., von Haeseler, A., and Lercher, M. J. (2012) TreeSnatcher plus: capturing phylogenetic trees from images. BMC Bioinformatics 13, 110

71. Kumar, S., Stecher, G., Li, M., Knyaz, C., and Tamura, K. (2018) MEGA X: Molecular Evolutionary Genetics Analysis across Computing Platforms. Mol. Biol. Evol. 35, 1547-1549 